\title{
Mathematical Psychology and Psychophysiology Meeting \\ Philadelphia, Pennsylvania \\ April 15-16, 1980
}

This meeting is sponsored by the American Mathematical Society and the Society for Industrial and Applied Mathematics. The organizing committee is: W. K. Estes, Harvard University: R. D. Luce, Harvard University; S. Grossberg, Boston University; M. F. Norman, University of Pennsylvania; H. Simon, Carnegie-Mellon University; and G. Sperling, New York University. The speakers include: G. Carpenter, Northeastern University; W. Freeman, University of California, Berkeley; S. Geman, Brown University; N. Graham, Columbia University and University of Oregon; S. Grossberg, Boston University; G. J. Iverson, New York University; D. Krantz, University of Michigan; R. D. Luce, Harvard University; C. von der Malsburg, Göttingen; L. Narens, University of California, Irvine; D. Noreen, Bell Labs; M. F. Norman, University of Pennsylvania; and G. Sperling, New York University.

The meeting will be held in the Betsy Ross Suite, Benjamin Franklin Hotel, Chestnut Station and 9th Street, Philadelphia. Registration begins at 8:00 a.m. on April 15. Inquiries should be sent to Dorothy Smith, Ameriçan Mathematical Society, P.O. Box 6248, Providence, Rhode Island 02940.

\section{XVIIth International Ethological Conference \\ September 1-9, 1981 \\ Oxford, England}

The U.S. Committee of the International Ethological Conference wishes to broaden the base of participation in the biannual meeting and, hence, is inviting applications from psychologists whose interests are highly relevant to ethology. U.S. participation is restricted to 110 delegates. Potential delegates are voted on by a committee of nine persons. Those receiving the highest ranking receive invitations, irrespective of previous participation. (As many as 400-500 persons are expected to compete for the 110 invitations.) Those who submit applications should be prepared to pay their complete travel and lodging expenses. Of the 110 delegates from the U.S.A., $25 \%$ will be graduate students and recent postdocs ( $\leqslant 3$ years postdoctoral experience).

To be placed on the mailing list for an application form, at this time merely send your name and address to

\author{
Dr. Marc Bekoff \\ Department of EPO Biology \\ University of Colorado \\ Boulder, Colorado 80309
}

Application forms and full instructions will be mailed in due course. 